\title{
Del Club del Progreso al Jockey Club: transformación y refinamiento de los espacios de sociabilidad de la burguesía de Buenos Aires (1852-1882) \\ From the Club del Progreso to the Jockey Club: Transformation and Refinement of the Spaces of Sociability of Buenos Aires Bourgeoisie (1852-1882)
}

\author{
Santiago Javier Sánchez \\ Université de Montréal \\ santiago.javier.sanchez@umontreal.ca
}

Recibido: 6-VI-2014

Aceptado: 20-I-2015

\section{Resumen}

El Club del Progreso, fundado en 1852, fue el primer espacio exclusivo de sociabilidad con el que contó la burguesía de Buenos Aires. Concebido como un sitio refinado y europeizante, contribuyó a la forja de una identidad de clase y al rol protagónico de una elite política y económica. Así lo revelan las fuentes histórico-literarias, las cuales dan cuenta también de la posterior fundación del Jockey Club (1882), un espacio aún más refinado que logró, al fin, convertirse en el lujoso escenario de una burguesía porteña ya consolidada.

Palabras clave: Clubes, Club del Progreso, Jockey Club, Sociabilidad, Burguesía, Buenos Aires, Siglo XIX.

\begin{abstract}
The Club del Progreso, founded in 1852, was the first exclusive space of sociability of Buenos Aires bourgeoisie. It was conceived as a refined and European place, and it contributed to the forging of a class identity and to the leading role of a political and economical elite. Historic and literary sources reveal this situation, and also testify to the foundation of the Jockey Club (1882), a space even more refined which turned into the luxurious scene of a consolidated 'porteña' bourgeoisie.
\end{abstract}

Keywords: Clubs, Club del Progreso, Jockey Club, Sociability, Bourgeoisie, Buenos Aires, 19th Century. 


\section{Introducción}

En este artículo analizaremos un espacio de sociabilidad característico de la alta sociedad porteña desde 1852: los clubes sociales. De manera paralela estudiaremos el proceso de educación y de refinamiento llevado adelante por este grupo durante la segunda mitad del siglo XIX así como el rol social de la arquitectura y de los espacios interiores. Nos centraremos en el Club del Progreso y en el Jockey Club de Buenos Aires, recurriendo sobre todo al testimonio aportado por la novela La Gran Aldea (1884) de Lucio V. López. Esta obra costumbrista, en la que se entremezclan las pinceladas autobiográficas con la crónica político-social, relata los profundos cambios sufridos por Buenos Aires entre 1852 y 1884. A través del relato en primera persona del protagonista, un huérfano perteneciente a la rama pobre de una rica y linajuda familia porteña, López muestra la declinación moral de la alta sociedad, paralela a su enriquecimiento, a su europeización y a su desnacionalización. Pero además de mostrar el envilecimiento de una clase social prestigiosa, la misma que dirigiera la Revolución de 1810 y la Guerra de Independencia, López describe los cambios operados en la fisonomía urbana, en la arquitectura, en los comercios, en la vestimenta y en los objetos en general. La Gran Aldea es así un análisis de los cambios estéticos de la alta sociedad local, de una pobreza espartana antes de 1880 y derrochadora y ostentadora en los años finiseculares.

En este trabajo proponemos que las sociabilidades fueron, desde la era criolla, un ámbito privilegiado de construcción de identidades colectivas, tanto en los sectores más pudientes como en los populares. Como primera hipótesis sostenemos que durante la era criolla ambas identidades de clase habrían estado íntimamente entrelazadas. Aunque también era dado reconocerlas por separado, su interdependencia habría sido considerable. Una segunda hipótesis es que, al principiar la era aluvial, estas identidades se habrían definido más, en especial la de la "alta sociedad", y con ellas las sociabilidades conexas ${ }^{1}$.

En cuanto a los conceptos que utilizaremos conviene aclarar que el término "clase" entraña obstáculos analíticos difícilmente superables². Términos como "clase alta", "elite", "aristocracia" o "burguesía" adolecen de una cierta ambigüedad teórica. Ni siquiera la tradición marxista, que es la que más ha utilizado la palabra-concepto de "clase", ha sido capaz de brindar una definición

1. "Era criolla" (1810-1853) y "era aluvial" (desde 1853 hasta el presente) son dos periodizaciones y dos conceptos acuñados por José Luis Romero (1956). Al respecto ver ROMERO, José Luis, Las ideas políticas en Argentina, Buenos Aires, Fondo de Cultura Económica, 2010 (1965), pp. 13-14 y 65-66.

2. Al respecto, consultar LOSADA, Leandro, La alta sociedad en la Buenos Aires de la Belle Époque, Buenos Aires, Siglo Veintiuno Editores Iberoamericana, 2008, p. XX. 
precisa. Lo único claro pareciera ser que lo económico es lo determinante. Siendo que expresiones como "clase alta" y "aristocracia" son entendidas más como calificativos que como definiciones, Leandro Losada opta, al igual que otros estudiosos de la Belle Époque, por "alta sociedad". Este concepto, que adoptaremos también, permite identificar a un personaje de la vida social, aún a despecho de su heterogeneidad. Pese a su pluralidad, los miembros de la "alta sociedad" estaban unificados por un estilo de vida, así como por ciertas pautas culturales, con sus pasatiempos y ritos, marcados a su vez por una pretensión de distinción, refinamiento y exclusividad ${ }^{3}$.

El concepto de "sociabilidad", por su parte, está presente en la tradición filosófica inglesa y francesa desde el siglo XVII pero, en lo que hace a los estudios históricos, fue Maurice Agulhon quien lo utilizó por primera vez en su estudio sobre las confraternidades y asociaciones de la Provenza meridional de 1850$1900^{4}$. Más tarde, Pilar González Bernaldo ${ }^{5}$ lo emplearía para analizar la vida social del Buenos Aires de 1829-1862. En los diccionarios franceses el término sociabilité puede entenderse en tres niveles, el de la especie, el del individuo y el del "hombre sociable", colectivamente considerado. Es este último sentido el que interesa al historiador, y el que nosotros adoptaremos. Así, puede contraponerse al francés con el extranjero, al parisino con el provenzal, o al francés del XVIII con el del XVII o XIX. Al volverse colectiva, sujeta a variaciones en el espacio y el tiempo, la sociabilidad deviene un objeto de historia posible ${ }^{6}$.

Puede decirse que la alta sociedad ha sido escasamente tratada por los estudiosos en la Argentina. Mayor atención, en cambio, han merecido los sectores populares e inmigratorios ${ }^{7}$. En lo que hace al estudio de las capas sociales más encumbradas, el interés académico se ha centrado en las temáticas más estrictamente económicas, como la tenencia y explotación de la tierra, el desarro-

3. LOSADA, Leandro, La alta sociedad..., p. XXI.

4. AGUlHON, Maurice, La sociabilité méridionale. Confréries et associations en Provence orientale dans la deuxième moitié du XVIIIe siècle, 2 v., Paris, 1966.

5. GONZÁLEZ BERNALDO, Pilar, "Vida privada y vínculos comunitarios: formas de sociabilidad popular en Buenos Aires, primera mitad del siglo XIX", DEVOTO, Fernando; MADERO, Marta (dirs.), Historia de la vida privada en la Argentina. Tomo I. País antiguo. De la colonia a 1870, Buenos Aires, Taurus, 1999 y Civilidad y política en los orígenes de la nación argentina, 1829-1862, Buenos Aires, Fondo de Cultura Económica, 2001.

6. AGULHON, Maurice, La sociabilité méridionale..., pp. 14-16.

7. Un trabajo clásico es el de ROMERO, Luis Alberto; GUTIÉRREZ, L., Sectores populares y cultura política. Buenos Aires en la entreguerra, Sudamericana, 1995. En lo que hace a la inmigración, la bibliografía existente es tan vasta como inabarcable. Una obra de síntesis muy útil es la de DEVOTO, Fernando, Historia de la inmigración en la Argentina, Buenos Aires, Sudamericana, 2003. 
llo industrial y la cuestión obrera ${ }^{8}$. Menos abundantes son los trabajos focalizados en el estilo de vida y en las sociabilidades. La investigación más completa, que ha colmado este vacío, es el libro de Leandro Losada. Para cuestiones más puntuales, como los clubes, existe un puñado de artículos en revistas académicas o en obras colectivas ${ }^{9}$. Es en este último dominio parcial que se inscribe nuestra investigación. Como aporte original, este artículo busca incorporar la dimensión literaria al análisis histórico ya realizado sobre los clubes de la alta sociedad porteña, en especial el Club del Progreso. La riqueza de perspectivas diferentes y "no oficiales" de la novela La Gran Aldea permite, más que complementar las fuentes de la época o los trabajos historiográficos, ofrecer una visión para nada convencional de estas instituciones decimonónicas. El interés de la novela de López trasciende lo literario, ya que, siendo este autor un miembro de la alta sociedad y del Club del Progreso, su testimonio ácido ausculta y desacraliza este espacio de sociabilidad. La mirada de conjunto que dedica López a su grupo social echa por tierra sus valores sustentadores, objetando el proyecto de nación liberal del Ochenta ${ }^{10}$.

Otro de los conceptos históricos que utilizaremos es el de "patriciado criollo". Entendemos por tal al sector social más poderoso de la Buenos Aires colonial, constituido por funcionarios menores y por comerciantes-contrabandistas. A partir de la creación del Virreinato del Río de la Plata en 1776 y de la habilitación de Buenos Aires, su flamante capital, como puerto autorizado por la Corona española, el patriciado criollo comenzaría a desaparecer. A las familias fundadoras de la ciudad se agregarían entonces los comerciantes recién llegados, provenientes en su mayoría del norte de España, así como los miembros de una burocracia peninsular más elevada. El crecimiento material y demográfico de Buenos Aires aceleraría el nacimiento de la alta sociedad, la cual seguiría con-

8. Entre los numerosos trabajos específicos podemos citar BOTANA, Natalio, El orden conservador, Buenos Aires, Hyspamérica, 1986; HORA, Roy, Los terratenientes de la pampa argentina. Una historia social y política, 1860-1945, Buenos Aires, Siglo XXI, 2002; ZIMMERMANN, Enrique, Los liberales reformistas. La cuestión social en Argentina, 18601945, Buenos Aires, Sudamericana/Universidad de San Andrés, 1995.

9. KORN, Francisco, "La gente distinguida", ROMERO, Luis Alberto; GUTIÉRREZ, L., Buenos Aires. Historia de cuatro siglos, Buenos Aires, Abril, 1983, tomo II; EDSAL, T.M., Elites, Oligarchs and Aristocrats: The Jockey Club of Buenos Aires and the Argentine Upper Classes, 1920-1940, tesis de doctorado, Tulane University, 1999. En lo que respecta al Club del Progreso, al celebrarse los 150 años de su fundación, fue publicado el volumen colectivo Club del Progreso 1852-2002. Sesquicentenario, Buenos Aires, Ediciones Lumiere, 2002, en el que escribieron varios historiadores.

10. La expresión "Gran Aldea" fue creada por Lucio V. López al escribir la novela homónima y hace alusión a la pequeña ciudad de Buenos Aires anterior a 1880. Su uso se generalizó a posteriori entre numerosos autores. 
solidándose durante el siglo XIX, recibiendo en su seno a nuevos integrantes. Entre los mismos figurarían inmigrantes enriquecidos o familias provincianas de abolengo llegadas a Buenos Aires tras la federalización de la ciudad en 1880. Sobre comienzos del siglo XX, en tanto, la alta sociedad, convertida en una auténtica aristocracia, cerraría filas. Ya para ese entonces no sólo habría culminado el proceso de educación y refinamiento del que trataremos, sino que además los territorios arrebatados a los indígenas ya habrían sido ocupados y explotados, por lo que el impulso de la economía argentina se ralentizaría. Téngase en cuenta que la base de esta economía fue siempre agroexportadora, y que el desarrollo industrial fue limitado. La preeminencia consecutiva de una serie de productos de exportación marcaría la historia económica del país. Durante la época colonial, los cueros vacunos constituyeron la base de la producción rioplatense. En los albores de la Independencia, la carne salada revolucionaría el mercado local, para ser luego reemplazada por la lana ovina. Sobre fines del XIX, en tanto, la agricultura a gran escala -especialmente el trigo- y la carne vacuna refinada conquistarían el mercado internacional. La alta sociedad porteña, constituida a partir del comercio, se volcaría a la adquisición de tierras y a la producción agropecuaria.

Con el objeto de facilitar la exposición y la lógica analítica de nuestro trabajo lo hemos subdividido en cinco apartados. El primero de ellos es esta introducción. En el segundo de los apartados ("La nueva arquitectura decimonónica y la transformación de los espacios interiores en Buenos Aires"), hablaremos de los cambios que sufrió la arquitectura residencial de la burguesía porteña a partir de 1880 , particularmente el reemplazo de la casona colonial por el palacete de inspiración francesa. Nos centraremos en el análisis de los flamantes interiores, más sofisticados y especializados, concebidos ahora según la noción de hogar (home). En el tercer apartado ("De las tertulias políticas al Club del Progreso"), hablaremos del significado de la fundación del Club del Progreso en 1852, el cual iniciaría una nueva etapa en la sociabilidad de los sectores más adinerados de Buenos Aires. Describiremos además la arquitectura del Palacio Muñoa, que fuera su sede entre 1858 y 1900 y que expresara las tendencias decorativas del momento. Valiéndonos del relato de Lucio V. López, exploraremos la dimensión clasista y política de este espacio cerrado, contraponiéndolo con el de las más tradicionales tertulias políticas de la ciudad criolla, en especial aquella presidida por Medea Berrotarán, personaje clave de La Gran Aldea. En el cuarto apartado ("Del 'Club' al Jockey: la evolución de la dimensión interior") realizaremos una suerte de análisis comparativo entre el Club del Progreso y el Jockey Club fundado en 1882. Para el caso emplearemos, como fuentes históricas que complementarán y enriquecerán 
el testimonio de López, las cartas intercambiadas entre Carlos Pellegrini, presidente del Jockey Club, y Miguel Cané, embajador argentino en París, durante el período 1896-1897. Estas cartas, escritas poco antes de que se inaugurara la flamante sede del Jockey, contienen importantes datos y apreciaciones acerca del modo de organizar los espacios internos, la gastronomía y la servidumbre. A estas invalorables fuentes se añadirá el apoyo teórico-histórico de Adriana Bergero, Lucía Gálvez, Félix Luna y David William Foster, entre otros autores.

\section{La nueva arquitectura decimonónica y la transformación de los espacios internos en Buenos Aires}

Antes de introducirnos de lleno en la temática mencionada, conviene hacer referencia a una cuestión clave a la hora de entender las sociabilidades decimonónicas en Buenos Aires: la arquitectura doméstica. El centro tradicional de Buenos Aires estuvo ocupado originalmente por las familias de la alta sociedad, las cuales habitaban en casonas de habitaciones numerosas y de una sola planta alineadas a lo largo de tres o cuatro patios. Hasta el despegue económico que principió alrededor de 1850, Buenos Aires estuvo restringida dentro de los estrechos límites marcados por la segunda fundación de Juan de Garay en 1580, entre las actuales calles Balcarce, 25 de mayo, Viamonte, Maipú-Chacabuco y Chile. Fuera de las manzanas destinadas a los edificios principales, el resto se repartió entre los primeros pobladores en lotes de medias manzanas, solares o caballerías (cuadrados de 70 metros de lado) y cuartos (70 m x 17,5 m). Sobre estos últimos, que equivalían a dos lotes modernos, se levantaron las típicas casas coloniales, inspiradas en el modelo de la casa romana ${ }^{11}$.

Tras la epidemia de fiebre amarilla de 1870-1871, que segó la vida de 14.000 personas, las familias de la alta sociedad comenzaron a abandonar el centro y a construir sus mansiones en las parroquias del Socorro y la Merced, las que luego formarían el selecto Barrio Norte. Muchas de las casonas coloniales se convertirían en conventillos que albergarían a familias de bajos recursos. Esta situación se agudizaría con el crecimiento económico, la expansión demográfica fruto de la inmigración europea, la modernización y las reformas urbanísticas emprendidas por el intendente Torcuato de Alvear (1883-1887). En cuanto a las casas de la alta sociedad, durante el XIX se cerrarían paulatinamente sobre sí mismas. Las mansiones de fastuoso estilo europeo constituirían la culminación más acabada de este fenómeno. En las flamantes construcciones de la Avenida

11. MATAMORO, Blas, La casa porteña, Buenos Aires, Centro Editor de América Latina, 1971, p. 10. 
Alvear, arteria "propiamente habitacional o residencial"12, predominaría lo interior. Sólo el que viviera en ellas podría apreciarlas con plenitud, mientras que desde afuera no se vería lo que éstas ocultaban. Es lo que señala Matamoro, en su análisis histórico de la casa porteña:

"Son mansiones para admirar de lejos [...] Apenas el espectador se acerca a ellas, la espesura férrea de la reja italiana o Luis XV, la tapia estriada o la balaustrada de gruesas pilastras le impiden la visión. La casa puede ser vista de cerca sólo por quien tiene acceso a ella, pero ni siquiera los proveedores la conocen, ya que no pasan del comedor de servicio. Lejos han quedado los tiempos en que la puerta de la casona colonial estaba abierta todo el día, y se entraba hasta a caballo en su patio delantero, apenas guarnecido [...] por la sutil puntilla forjada de la cancela"13.

En las mansiones de la alta sociedad la fachada importaba más que el oculto interior, el cual se insinuaba a través de ella. La austeridad de las casonas coloniales, con sus fachadas encaladas y lisas, se transformó radicalmente, adoptando las exuberancias decorativas francesas e italianas. Así, los interiores se poblaron de objetos suntuarios, sin utilidad práctica, mera decoración o escenografía. En Buenos Aires la literatura refleja esta circunstancia: las novelas de Lucio V. López, Eugenio Cambaceres, Julián Martel y Carlos María Ocantos describen irónicamente la rimbombante decoración interna. La alta sociedad inició un estilo arquitectónico que le sería peculiar: el de los petits hôtels o palacios franceses, los cuales requerían de un gran espacio, a veces incluso de una manzana entera, y que contrastaban agudamente con el resto de la ciudad signado por la superpoblación y la promiscuidad. De esta forma, la alta sociedad porteña gozó de espacios y de lujos mayores que los de la etapa criolla. El abismo con respecto a los sectores subalternos se ahondó.

Hay que decir también que, mientras el patriciado criollo obtenía su legitimidad de espadas, uniformes y guerras, la nueva generación, más mundana, dependía de fiestas de gala de sociedad, las cuales requerían de lugares apropiados. Los mejores exponentes arquitectónicos que cubrieron esta necesidad los encontramos en un espacio reducido del Barrio Norte, a lo largo de la Avenida Alvear y de la Plaza Pellegrini. Allí se levantaron, a partir de 1880, el Palacio Pereda, las Residencias Duhau y Unzué de Casares, el Alvear Palace Hotel y el Palacio Anchorena, entre otros ${ }^{14}$.

12. RAMOS, Julio, Desencuentros de la modernidad en América Latina. Literatura y politica en el siglo XIX, México, Fondo de Cultura Económica, 1989, p. 130.

13. MATAMORO, Blas, La casa porteña..., p. 48.

14. BERGERO, Adriana, Intersecting Tango. Cultural Geographies of Buenos Aires, 1900-1930, Pittsburgh, University of Pittsburgh Press, 2008, pp. 26-27. 
Ciertamente, las casonas coloniales poseían gran espaciosidad pero su lujo y su confort eran escasos. Los petits hôtels no sólo fueron más impactantes en lo estético sino que además ofrecieron interiores más numerosos y diversificados. Por empezar, contaron con más de un piso, y no con una sola planta, como ocurría en la casi totalidad de las casonas tradicionales. La especialización de los espacios enriquecería la dimensión interior. En cada mansión de la alta sociedad habría un salón, un vestíbulo, ascensores, comedor, fumoir, jardines, escritorios, cuartos autónomos y personales, con al menos un baño cada dos de ellos, calefacción, despensas, bodegas, cuartos de servicio, cocina en los altos, etc.

Este confort sistematizado no era sólo un símbolo de estatus sino que respondía a una idea nueva. El "confort", tal como hoy lo entendemos, concibe el ámbito residencial como la encarnación del espacio privado de la familia, una concepción que en Occidente recién se fue abriendo paso a lo largo del XVIII. Por ello durante este siglo, pero mucho más durante el XIX, la casa se convierte en hogar, en home, vivienda y solaz a la vez ${ }^{15}$. El confort hogareño se vincula a la intimidad, cuya necesidad aumenta y lleva a la multiplicación de cuartos, una buena parte de los cuales está destinado a la servidumbre. Al mismo tiempo, crece la distancia entre las habitaciones de los patrones y de los sirvientes, y entre los espacios femeninos y masculinos. Los fumoirs se definen a sí mismos como espacios eminentemente masculinos, en donde los hombres se reúnen a fumar y a charlar de sus asuntos, tal como ya lo están haciendo, fuera del hogar, en los clubes sociales de inspiración inglesa. Por otra parte, la introducción de la iluminación a gas en la década de 1880 y de la luz eléctrica hacia 1900 contribuye a aumentar el confort.

La casa burguesa arquetípica de la Generación del Centenario adoptó estos lenguajes espaciales, burocratizando las relaciones interpersonales y compartimentando a los grupos sociales que interactuaban dentro de la mansión. De alguna forma, las distancias espaciales hacían eco de las separaciones análogas que el Orden Conservador vigente imponía en el dominio público. Tal polarización espacial en las residencias de la alta sociedad no hace más que enviar a la ciudad colonial al pasado, estableciendo en su interior una estructura semiótica que es instrumental en la configuración de las relaciones interpersonales domésticas. El realineamiento social introducido por la modernización estuvo regulado por un arsenal de medios en varias esferas de la vida pública y política, incluyendo los planos de las mansiones, los cuales proveyeron de material a las fronteras internas que la alta sociedad buscó para Buenos Aires y para el resto del país ${ }^{16}$.

15. Ibid., p. 85.

16. Ibid., pp. 38-40. 
En lo que respecta a las sociabilidades de la alta sociedad porteña, la fundación del Club del Progreso en 1852 marcó una divisoria de aguas. Para Jorge Myers, que el ámbito privilegiado para los intercambios interpersonales dejara de ser el ámbito residencial significaría el paso gradual de la familia a la clase como eje de sociabilidad ${ }^{17}$. El mero hecho de que la alta sociedad porteña contara al fin con un espacio apropiado para celebrar concurridos banquetes y bailes implicó un profundo cambio en las costumbres ${ }^{18}$. Aún así, la situación se modificaría con el correr de los años. Si bien en 1882 fue fundado el Jockey Club y en 1897 se inauguró su fastuosa sede -muy superior a la del Club del Progreso- con un baile que hizo historia, la proliferación de los petits hôtels provocó una disminución en el número de bailes organizados por estas instituciones y un regreso a los ámbitos residenciales. Para ese entonces las mansiones contaban con salones lo suficientemente espaciosos como para organizar eventos sociales de calidad, lo que confirió a las mujeres un mayor protagonismo. La casa volvió a ser, como en la era criolla, el espacio femenino por definición, mientras que los clubes se tornaron más exclusivamente masculinos ${ }^{19}$.

Sobre fines del XIX la alta sociedad porteña se amplió al incorporar inmigrantes exitosos y provincianos ligados al aparato político, por lo que hubo una mayor necesidad de salones, que los clubes solos no podían brindar. Aún así, y a despecho de lo que señala cierta literatura contemporánea (Martel, Cambaceres, Ocantos) en la que se narra el triunfo de los advenedizos foráneos y el terror "invasivo" que experimentaba la alta sociedad, lo cierto es que los testimonios de los visitantes extranjeros muestran que las familias criollas y sus residencias eran "fortalezas prácticamente inexpugnables", y que los burgueses porteños eran muy reticentes a la hora de llevar extraños a sus hogares, poniéndolos en contacto con sus mujeres e hijas ${ }^{20}$. Las nuevas mansiones,

17. MYERS, Jorge, "Una revolución en las costumbres: las nuevas formas de sociabilidad de la elite porteña, 1800-1860", DEVOTO, Fernando; MADERO, Marta (dirs.), Historia de la vida privada en la Argentina..., p. 133.

18. Una simple mirada a la lista de miembros fundadores del Club del Progreso nos da la pauta de su composición social. Entre ellos figuran personajes insignes de la alta sociedad de Buenos Aires, como Diego de Alvear, hijo del célebre general de la Independencia y Director Supremo de las Provincias Unidas del Río de la Plata, Carlos María de Alvear; Santiago Calzadilla, padre del militar y memorialista del mismo nombre; el escritor José Mármol, autor de la novela Amalia; el estanciero José J. Martínez de Hoz, antepasado de José Alfredo Martínez de Hoz, Ministro de Economía de la dictadura militar entre 1976 y 1981; el diplomático, memorialista y militar Tomás Guido, de actuación destacada durante la Guerra de Independencia, y Miguel Cané, padre del escritor del mismo nombre y futuro embajador argentino en París.

19. LOSADA, Leandro, La alta sociedad..., p. 263.

20. Ibid., p. 268. 
insistimos, ayudaban mucho en este aspecto. A diferencia de las antiguas residencias coloniales, los petits hôtels detentaban un formato arquitectónico de mayor recogimiento, inviolabilidad e intimidad, al que se agregaba el rol de la etiqueta y de la servidumbre. Este formato tendría su correlato en los clubes sociales, como veremos a continuación.

\section{De las tertulias políticas al Club del Progreso}

El primer club social con el que contó la ciudad de Buenos Aires data de 1844. Nos referimos al Club de Residentes Extranjeros, al que los criollos tenían vedado el acceso, y que se hallaba ubicado en la calle San Martín, frente a la Catedral. En su interior había amplios salones, una nutrida biblioteca y una hemeroteca que poseía publicaciones periódicas extranjeras y nacionales. Semanas después del derrocamiento de Juan Manuel de Rosas, el 25 de marzo de 1852, Diego de Alvear, miembro de una de las familias más encumbradas de la ciudad, convocó a 56 vecinos e impulsó la fundación del Club del Progreso, el cual nacería oficialmente el $1^{\circ}$ de mayo y marcaría toda una época. El "Club", como se lo conocería familiarmente, sería sobre todo porteño y criollo, aunque abierto también a los notables provincianos establecidos en la Capital y a los inmigrantes enriquecidos. El europeísmo, la distinción, el espíritu aristocrático, no le serían en absoluto ajenos, pero obrarían más bien como modelos ideales a los que se intentaría imitar con torpeza. Es lo que nos sugiere Lucio V. López en su novela La Gran Aldea, de 1884:

"Es en un baile del Club Progreso donde pueden estudiarse por etapas treinta años de la vida social de Buenos Aires: allí han hecho sus primeras armas los que hoy son abuelos. La dorada juventud del año 52 fundó ese centro del buen tono, esencialmente criollo, que no ha tenido nunca ni la distinción aristocrática de un club inglés ni el chic de uno de los clubs de París. Sin embargo, ser del Club del Progreso, aún allá por el año 70, era chic, como era cursi ser del Club del Plata"21.

El efímero Club del Plata, sito en la esquina de Chacabuco y Victoria, fue un desprendimiento del Club del Progreso, producto de los resquemores entre unitarios y federales. Fueron estos últimos los que intentaron crear una entidad que los representase políticamente, más allá de los ideales amplios y conciliadores del Club del Progreso. Pero el Club del Plata, cuyo primer presidente fue Bernardo de Irigoyen, nunca contó con demasiados socios y su presupuesto limitado le impidió erigirse en símbolo y lugar de encuentro de los sectores

21. LÓPEZ, Lucio Vicente, La Gran Aldea, Buenos Aires, Colección "Los recobrados", Capital Intelectual, 2010 (1884), p. 89. 
más pudientes. Al mismo tiempo, hubo otros "clubes" de duración aún más limitada, que aparecían en vísperas de los comicios nacionales o provinciales, asociados a una facción y a un caudillo, para desaparecer luego. Solían contar con un periódico que defendía ardientemente la candidatura de turno, atacando con saña, sin escatimar insultos y calumnias, a la facción opuesta. Pero veamos cuáles fueron los objetivos fundacionales del "Club", expresados por Diego de Alvear al director de La Tribuna y publicados en este diario el 3 de septiembre de 1853:

" $1^{\circ}$ - Desenvolver el espíritu de asociación, completamente extinguido entonces, con la reunión diaria de los caballeros más respetables tanto nacionales como extranjeros; $2^{\circ}$ : Borrar prevenciones infundadas, creadas por el aislamiento y la desconfianza, uniformando, en lo posible, las opiniones políticas por medio de la discusión deliberada y $3^{\circ}$ - Mancomunar los esfuerzos de todos hacia el progreso material y moral del país"22.

Lo que pretendía Alvear era propiciar el desenvolvimiento del espíritu asociativo entre los hombres de la alta sociedad de Buenos Aires, reuniendo en un ámbito de encuentro apolítico a las facciones irreconciliables y promoviendo el desarrollo económico y ético del país. Así, el objetivo prioritario que animó la creación de esta entidad se vincula con una voluntad expresa de pacificación, civilización y civilidad. Para Félix Luna, este objetivo fue alcanzado plenamente por vía de la misma sociabilidad que propiciaba el Club, ya que también las fiestas y los bailes podían ser "instrumentos de pacificación". El hecho de estar obligados a coincidir pacíficamente en un ámbito gobernado por reglas de convivencia social, aligeraba las pasiones incendiarias de la política y de la guerra. El Club se erigió así en un "espacio de civilidad" más eficaz que los discursos y proclamas ${ }^{23}$.

El Reglamento de esta institución prohibía las discusiones partidarias y aceptaba la diversidad ideológica de sus miembros, lo cual no impidió que las conversaciones y alianzas políticas siguieran teniendo lugar en sus salas. Aquel año 1852 fue uno de los más conflictivos de la historia argentina. El país se desangraba entre las facciones opuestas de urquicistas partidarios del Litoral y de autonomistas porteños que se insultaban en la prensa o se enfrentaban en el campo de batalla. Tal circunstancia se prolongó hasta 1861. Las crónicas periodísticas de los bailes organizados por el Club, que no tardaron en convertirse en el gran evento de la alta sociedad porteña, alternaron con los partes

22. LASCANO QUINTANA, Guillermo, "Dos historias del Club", Club del Progreso 18522002. Sesquicentenario, Buenos Aires, Ediciones Lumiere, 2002, p. 132.

23. LUNA, Félix, "El medio siglo del Club", Club del Progreso 1852-2002. Sesquicentenario, Buenos Aires, Ediciones Lumiere, 2002, pp. 92-93. 
de las batallas, a tal punto que, entre 1861 y 1862, fueron suspendidos los bailes hasta nuevo aviso, debido a la guerra que enfrentó al Estado de Buenos Aires con la Confederación Argentina ${ }^{24}$. La misma palabra "Progreso", escrita con mayúsculas, nos revela un concepto clave, una "idea-fuerza" de la época que se cristaliza en la denominación del Club. Tal como señala Lucía Gálvez, "Progreso" era un vocablo mágico, cuyo significado estaba por encima de las diferentes aspiraciones, simbolizando el acceso a la modernidad europea, a la técnica, a la ciencia, a la prosperidad, la panacea para todos los males que padecía el país y el ambiente imprescindible para que la sociedad se desarrollase de manera pacífica y ordenada ${ }^{25}$.

Pero el rasgo definitorio más saliente del Club era más clasista que político, ya que pretendía ser el recinto de formación de una "elite cultural". Este concepto se vincula a la noción contemporánea de "gente decente", en lo que hace a la educación política y los buenos modales. La expresión "elites culturales" agrega la idea de una posición preeminente y de vinculación directa con la cosa pública. Según González Bernaldo, habría una relación entre las prácticas de sociabilidad de las elites porteñas de la primera mitad del XIX y la formación republicana. Durante este período, circuló entre los miembros de los sectores dominantes un "discurso sobre la sociabilidad", vinculado con las relaciones "civiles" formadoras del lazo social ${ }^{26}$. El Club del Progreso sería una prueba palpable. Para López, sin embargo, la situación era distinta. En La Gran Aldea la evocación del Club no deja de ser negativa. El paso de los años no habría hecho más que ahondar el contraste entre el ayer juvenil y patriótico de una clase que se vanagloriaba de ser la constructora de una nación y su vulgar presente, signado por el vacío existencial:

"Muchas matronas de peso, que hoy han trepado la cima de los cincuenta, eran criaturas adorables entonces y esperaban con las manos llenas de flores y coronas el desfile de sus guerreros predilectos, hoy maridos vichocos o solterones embalsamados, que purgan el delito de su inconstancia en el Club del Progreso reflexionando sobre una mesa de dominó"27.

De la lectura de La Gran Aldea puede inferirse que la sociedad porteña se hallaba fervorosamente politizada, en particular el sector que detentaba el poder

24. GÁLVEZ, Lucía, Club del Progreso. La sociedad, los hombres, las ideas, 1852-2000, Buenos Aires, 1999, p. 35.

25. GÁlVEZ, Lucía, Club del Progreso..., p. 36.

26. GONZÁLEZ BERNALDO, Pilar, Civilidad y política en los orígenes de la nación argentina: las sociabilidades en Buenos Aires, 1829-1862, Buenos Aires, Fondo de Cultura Económica, 2001, p. 17.

27. LÓPEZ, Lucio V., La Gran Aldea..., p. 50. 
económico. El Club fue creado con la intención de contrarrestar tal virulencia, la cual sin embargo siguió desplegándose de manera espontánea en los espacios de encuentro más informales, como las tertulias políticas de las tiendas. Los comercios oficiaban como centros de sociabilidad y como virtuales constructores de identidades colectivas. López menciona el caso de don Narciso Bringas, notable tendero de Buenos Aires, orgulloso de su condición de porteño:

"Entre los príncipes del mostrador porteño el más célebre sin disputa, era don Narciso Bringas: gran tendero, gran patriota, nacido en el barrio de San Telmo, pero adoptado por la calle del Perú como el rey del mostrador. No había mostrador como el de aquel porteño: todo el barrio junto no era capaz de desdoblar una pieza de madapolán y de volverla a doblar como don Narciso; y si la pirámide misma le hubiera querido disputar su amor a Buenos Aires, a la pirámide misma le habría disputado ese derecho"28.

La pirámide a la que hace alusión el fragmento es la "Pirámide de Mayo", primer monumento patrio que tuvo Buenos Aires, inaugurado en 1811 y emplazado en el centro de la Plaza de la Victoria, esto es, frente al Cabildo. Antes de 1883 y de la creación de la Plaza de Mayo, surgida de la demolición de la Recova y de la fusión de las plazas de la Victoria y del Fuerte, este monumento representaba un patriotismo más porteño que argentino, un orgulloso localismo que los hombres como Narciso Bringas defendían con tesón.

Se comprende entonces por qué este personaje, tan sardónicamente retratado por López, fuera un entendido en política y un protagonista de la misma. Como "gran patriota" que era participó en la Revolución de Septiembre, la que en 1852 provocó la ruptura con Urquiza y la secesión de la provincia de Buenos Aires. También actuó en la batalla de Cepeda, que las tropas porteñas perdieron en 1859 frente al ejército de la Confederación Argentina. En la tertulia política de su tienda don Narciso procuraba explicar, noche tras noche, las razones del "desastre" a los habitués ${ }^{29}$. López pone en evidencia su tosquedad, no demasiado alejada de aquella ostentada por los caballeros del Club. Éstos, en definitiva, compartían con Bringas el mismo origen modesto y comercial, además de la condición de porteños y de criollos. El novelista apela así a la burla para desacreditar a estos personajes típicos de la Gran Aldea que se inmiscuían en la política sólo porque se sentían ricos, y porque pretendían ser los representantes de una ciudad protagónica.

La noche que llegó a Buenos Aires la noticia de la victoria porteña de Pavón la "tía Medea", uno de los personajes principales de La Gran Aldea, se enteró

28. Ibid., p. 41.

29. Ibid., p. 41.

Pasado y Memoria. Revista de Historia Contemporánea, 14, 2015, pp. 151-178 
en la misma tienda de Bringas, a la que había ido expresamente en busca de información. López, en la voz del narrador-testigo Julio Rolaz (sobrino de Medea), por entonces un niño, describe esta tertulia y otras análogas ubicadas en el centro comercial de la Gran Aldea:

"Mi tía Medea era gran parroquiana de lo de don Narciso y tenía esa inclinación garrulera, común en ciertas señoras, de departir con el tendero todas las novedades de la crónica del día. Aquella noche no se hablaba sino de política, y solamente los que hemos vivido bajo la atmósfera caliente del Buenos Aires de entonces, podemos apreciar la importancia que tenían las pláticas de los mostradores de la calle del Perú y de la calle de la Victoria"30.

En este pasaje de la novela ocurre un incidente desagradable que ejemplifica muy gráficamente lo que señalamos más arriba acerca de la intolerancia política y de la violencia armada que el Club intentó contrarrestar. Uno de los tertulianos preguntó a Medea si Julio era su hijo y al enterarse de que no era así, de que era sobrino de un urquicista fallecido, le lanzó una frase que el niño no entendió pero que el narrador adulto condena políticamente:

"-iAh! Adiós, amiguito -me dijo el señor curioso, que tanto se interesaba por saber de mí, tomándome del brazo y deteniéndome mientras mi tía ya pisaba la calle-adiós... cuatro balas merecía éste como el padre -agregó en el mismo umbral de la puerta, frunciendo el gesto. Yo me escurrí y me prendí del brazo de mi tía, llevando impresa la fisonomía de aquel señor, en quien había tenido la desgracia de levantar tanto odio y tanta pasión de venganza"31.

El partido de Medea y de los tertulianos de don Narciso es el de la alta sociedad local posterior a Rosas y a Pavón, liderado por Bartolomé Mitre, al que López rebautiza en su novela como "general Buenaventura". Medea apoya a Mitre y a su facción, los cuales llevan adelante la última batalla para separar a Buenos Aires de la provincia y convertirla en una capital nacional independiente, entronizando un gobierno central vigoroso a expensas de la autonomía provincial. López militó en la posición opuesta, aquella que pretendía que Buenos Aires continuara siendo la capital de un gobierno provincial fuerte. Es así que en La Gran Aldea, como sostiene Foster, se realiza la caricatura grotesca de Medea como la intransigente madre de la república, evidenciando las convicciones políticas del autor escondidas detrás de la mirada inocente del niño testigo. Muchos lectores interpretaron las descripciones de Medea, sus diatribas, y las ridículas proclamas de los políticos que se reunían en su salón sólo en términos del debate entre los nacionalistas, esto es, los que apoyaban la federa-

30. LÓPEZ, Lucio V., La Gran Aldea..., p. 43.

31. Ibid., p. 47. 
lización de Buenos Aires, como Medea y compañía, y los autonomistas que querían retener a Buenos Aires como capital provincial ${ }^{32}$.

No obstante ello, la tía Medea debe ser considerada como punto de referencia de la entera sociedad que López está representando en este punto de vista de la novela, que es el de la "aristocracia criolla". Ésta se compone de los individuos que asumieron la gloria del derrocamiento de Rosas y de la reconstrucción republicana. Julio muestra a estos individuos como arrogantes, intolerantes y agresivamente anti-intelectuales ${ }^{33}$. Pero veamos la caracterización que hace López de este grupo:

"En el partido de mi tía, es necesario decirlo para ser justo, y sobre todo para ser exacto, figuraba la mayor parte de la burguesía porteña: las familias decentes y pudientes; los apellidos tradicionales, esa especie de nobleza bonaerense pasablemente beótica, sana, iletrada, muda, orgullosa, aburrida, localista, honorable, rica y gorda; ese partido tenía una razón social y política de existencia; nacido a la vida al caer Rosas, dominado y sujeto a su solio durante veinte años, había, sin quererlo, absorbido los vicios de la época, y con las grandes y entusiastas ideas de libertad, había roto las cadenas sin romper la tradiciones hereditarias. No transformó la fisonomía moral de sus hijos; los hizo estancieros y tenderos en 1850. Miró a la Universidad con huraña desconfianza, y al talento aventurero de los hombres nuevos pobres, como un peligro de su existencia; creó y formó sus familias en hogar lujoso [...] pero sin quererlo [...] conservó su fisonomía histórica, que era honorable y virtuosa, pero rutinaria y opaca. Necesitó su hombre y lo encontró: le inspiró sus defectos y lo dotó con sus méritos ${ }^{34}$.

Aunque el novelista enjuicie con severidad al grupo del que forma parte, no deja de oscilar entre la crítica severa y el elogio de clase. La larga serie de adjetivos con los que caracteriza a la alta sociedad así nos lo sugiere: ésta era para él iletrada, muda, orgullosa, aburrida, gorda, rutinaria y opaca, sin dejar de ser sana, elegante, honorable, histórica y virtuosa. Huelga decir que Lucio V. López estaba entroncado con la más rancia alta sociedad de Buenos Aires. Su abuelo, Vicente López y Planes, había sido poeta, abogado, combatiente durante las Invasiones Inglesas de 1806-1807, protagonista de la Revolución de Mayo, funcionario del primer gobierno independiente, autor de la letra del Himno Nacional y efímero gobernador de la provincia de Buenos Aires en 1852. Su padre, Vicente Fidel López, abogado, periodista, y miembro del Salón Literario de 1837 se destacó sobre todo como historiador.

32. FOSTER, David Wiliam, "La gran aldea as Ideological Document", Hispanic Review, Vol. 56, $\mathrm{N}^{\circ} 1$ (Winter), 1988, p. 79.

33. FOSTER, David W., La gran aldea..., p. 79.

34. LÓPEZ, Lucio V., La Gran Aldea..., pp. 21-23. 
De las reuniones en lo de Medea, mezcla de tertulias criollas, cotilleos sistematizados y supuesta política seria, salieron grandes resoluciones que en realidad estaban guiadas, según nos refiere López, por la hierática y despótica figura de Mitre, ausente físicamente de estos encuentros pero presidiéndolos desde su distancia. Es más, la presencia de Buenaventura-Mitre, como bien subraya Blasi, es una constante a lo largo de la novela ${ }^{35}$. Veamos entonces la evocación infantil de Julio Rolaz:

"En vida de mi tía, su casa era uno de los centros más concurridos [...] en ella se adoptaban las resoluciones trascendentales [...] Los grandes planes que debían imponerse al comité, para que éste los impusiera al público, salían de allí, y en su elaboración tomaban parte las cabezas supremas, que deliberaban como una especie de estado mayor, sin que los jefes subalternos tomasen parte en las discusiones" ${ }^{\prime 3}$.

López se muestra satírico y acerbo en sus descripciones, auténticos cuadros de costumbres en los que se muestran personajes más cercanos a la caricatura que al realismo psicológico. Más que caracteres, lo que retrata López son ideas o principios que estos personajes encarnan. Es lo que se advierte en el relato de una de estas veladas políticas, la cual transcurre en 1861, poco antes de que estallara la guerra. El encuentro es presidido por el doctor Benjamín Trevexo, abogado, periodista, y uno de los líderes de la facción del general Buenaventura, que Medea Berrotarán admira apasionadamente. Como objetivo principal de la reunión figura la confección de una lista de candidatos a diputados. El doctor Trevexo, al igual que Medea, encarna la era criolla y defiende las prerrogativas de su generación frente a las pretensiones de los hombres jóvenes e ilustrados. Es por ello que se opone a los libros, a la Universidad, y a las ideas liberales. En cambio, pondera las virtudes del periodismo local y de la educación práctica. Las ideas políticas de este personaje son reaccionarias en grado sumo, pero no revisten un carácter personal sino que representan al sector socioeconómico y a la facción política que López condena. Así, respecto de la reunión en lo de Medea, Trevexo reconoce que son pocos los asistentes, pero que así debe ser, ya que el número excesivo de militantes no es bueno para tomar decisiones de mando. Éstas deben ser urdidas por un grupo selecto, detentador de una alta responsabilidad que el simple elector o el soldado raso no pueden asumir. Mientras éstos se desangran en la lucha comicial o bélica, la elite se encarga de dirigir y de encarnar democráticamente al pueblo:

35. BLASI, Alberto Oscar, Introducción a Lucio V. López, Huemul, Buenos Aires, 1965, p. 30. 36. LÓPEZ, Lucio V., La Gran Aldea..., p. 24. 
"Aquí no estamos todos, pero no convendría que lo estuviéramos. Una cosa son las reuniones populares de los teatros y de las calles, otra cosa deben ser los actos de la dirección y de la marcha de nuestro partido: una cosa son las batallas en las guerrillas, en las cargas y en los entreveros, y otra cosa son las batallas en el cuartel general. El elector, el club parroquial, pueden ir valientemente al atrio a votar, porque no tienen responsabilidades; el soldado muere en el asalto, en la lucha cuerpo a cuerpo, la metralla lo quema y lo despedaza, pero muere sin responsabilidad. La responsabilidad de las grandes luchas electorales, como la de las grandes acciones de guerra, está en los generales [...] En la tribu los más fuertes, los más hábiles, asumen la dirección de agrupaciones humanas: el derecho positivo codifica la sanción de las legislaciones inéditas, del derecho natural y nosotros exclamamos: ¡el pueblo somos nosotros!"37.

Mientras el pueblo está condenado a la lucha en terreno abierto, con todos los riesgos que esto supone, la elite se reúne en los espacios exclusivos de la dimensión interior. Es en este ámbito íntimo donde unos pocos conocidos sociabilizan, deciden y forjan una autoridad política y una identidad colectiva. Una identidad que apela a nociones generales como "pueblo", "nación", "tradición", "república" que en realidad enmascaran las realidades particulares de un grupo, la alta sociedad, y de una ciudad, Buenos Aires.

Así vemos cómo, en un escenario tan tradicionalmente criollo como la casona de los Berrotarán la tía Medea era la anfitriona de una tertulia clasista, que se pretendía política y seria, sin ostentar la distinción de un salón europeo, como sí ocurriría con los petits hôtels. En la misma línea, las tiendas de las calles del Perú y de la Victoria, en el corazón de la Gran Aldea, marcaban un tipo específico de sociabilidad, sin dejar de albergar un tono violento y populachero que la elite, en proceso de refinamiento, combatiría con la fundación del Club. Pero como indica Ángel Rama la era criolla y la era aluvial, aunque se sucedieron la una a la otra, también coexistieron, solapándose ${ }^{38}$. Las tertulias de las casonas y de las tiendas coexistieron durante un tiempo con el Club e incluso en el interior de este último la tradición criolla siguió operando con una fuerza irresistible. ¿En qué medida el escenario físico, la materialidad, determinaría las nuevas conductas sociales? La respuesta la hemos anticipado parcialmente al hablar de la arquitectura de los petits hôtels. Siguiendo esta misma línea de análisis abordaremos, seguidamente, el caso del Club del Progreso en su dimensión interior, sobre la cual López dejara su propio testimonio.

37. Ibid., pp. 31-32.

38. RAMA, Ángel, La ciudad letrada, Santiago de Chile, Tajamar Ediciones, 2004 (1984). 


\section{Del "Club" al Jockey: la evolución de la dimensión interior}

El Club del Progreso tuvo una primera sede, más modesta, en Perú 135. Desde 1857, y hasta 1900, funcionó en los altos del llamado Palacio Muñoa, construido por dos prósperos comerciantes vascos, los hermanos Marcos y Miguel Muñoa. Éste es el edificio que describe Lucio V. López en La Gran Aldea. Ocupaba toda la esquina de Perú y Victoria (hoy Hipólito Yrigoyen). Poseía tres pisos, dos entrepisos, una fachada de estilo italianate revival y la novedad para la época de una azotea con mirador, desde la cual se dominaba panorámicamente la ciudad. Su arquitectura era imponente para la Gran Aldea de construcciones bajas y había sido concebida por el ingeniero inglés Edward Taylor ${ }^{39}$. En un pasaje de la novela de López, en donde se describe un baile en el Club, Julio Rolaz y la bella Blanca Montifiori contemplan la ciudad dormida, primero desde uno de los balcones del Palacio Muñoa y luego a través de sus ventanales. Desde esta posición privilegiada ambos personajes alcanzan a divisar la iglesia de San Francisco y el Cabildo:

"Eran las tres de la mañana, la luna en menguante ya, iluminaba los techos de la ciudad dormida, la calle estaba solitaria, los faroles de gas con su luz roja titilaban, formando desde la esquina del club hasta el Retiro una senda que parecía iluminada por candilejas [...] El reloj del Cabildo golpeó en aquel momento las tres de la madrugada y el eco de la campana se extinguió en el silencio de la noche [. . .] En aquel momento comenzaba a amanecer; el primer albor del día dibujábase tras de las torres de San Francisco y el horizonte empezaba a teñirse débilmente de tintas rojas. Nos levantamos de la mesa y nos acercamos a los cristales a admirar aquel cuadro sublime ante el cual empalidecían las luces del baile" ${ }^{40}$.

Es en el balcón que Blanca le transmite a Julio su cínica y materialista concepción de la vida, que contrasta con la poética escena. Julio le declara entonces sus sentimientos e intenta en vano conmover a su indiferente interlocutora, a quien besa ardorosamente. Ésta, aunque reconoce sentirse atraída por él, le aclara que nunca podrán casarse, debido a la pobreza de él. En cambio, no se manifiesta contraria a hacerlo con un hombre mayor al que no ame, si éste es rico. Como en otros pasajes del relato, hay aquí una anticipación de lo que vendrá, puesto que Blanca Montifiori terminará casándose con el viudo Ramón Rolaz, tío de Julio y heredero de la inmensa fortuna de su esposa Medea Berrotarán ${ }^{41}$. Tal como

39. BRANDARIZ, Gustavo A., "El Palacio Muñoa", Club del Progreso 1852-2002. Sesquicentenario, Buenos Aires, Ediciones Lumiere, 2002, p. 50.

40. LÓPEZ, Lucio V., La Gran Aldea..., pp. 101-104.

41. Ibid., p. 102. 
señala David William Foster, Blanca concretará su ambición y Julio la verá proseguir un extravagante estilo de vida a expensas del dinero y de los sentimientos. Durante el baile en el Club Blanca brilla en todo su esplendor, con su gélida belleza y su elegancia europea, que contrastan con la rústica sencillez y las iras de Medea en su tertulia político-criolla.

Pero volvamos a la descripción del Palacio Muñoa. Su edificio presentaba un volumen compacto, de base casi cuadrada, que en su planta baja contaba con locales comerciales. El Club, en tanto, funcionaba en el segundo y en el tercer piso. Ambas plantas eran de doble altura, con entrepisos en la parte de servicios y grandes salones de recepción en la esquina, con dimensiones de treinta metros. La fachada consistía en un piano mobile con balcón corrido, que terminaba en una gran cornisa florentina. Su estilo italianate revival era la versión inglesa del "neo renacimiento italiano", uno de los estilos historicistas del XIX pero romántico y progresista a la vez, ya que simbolizaba la Florencia del Quattrocento y la libertad creativa del artista. Este estilo no dudaba en incorporar nuevas técnicas y materiales, como el hierro fundido, el acero, las puertas, las ventanas, los tirantes y las tablas producidas en serie. En Inglaterra, el italianate revival se expresó en dos clubes, el Traveller's (1829-1832) y el Reform Club (1837-1841) del arquitecto Charles Barry ${ }^{42}$.

En lo que hace a los interiores Taylor diseñó los espacios, pero la decoración posterior no fue suya. Aquí ya no encontramos la austeridad del italianate revival sino el gusto victoriano o francés de la segunda mitad del XIX ${ }^{43}$. Aprovechando el viaje a Europa de uno de los socios del Club, el señor del Sar, se compraron allí objetos lujosos: una alfombra de 33,5 m x 2,5 m de la Manufacture Royale D'Aubusson, seis arañas de bronce dorado fuego con bombas de 36 a 40 luces (de gas), 24 brazos de pared de cinco luces con bombas, y 14 cortinas de seda ${ }^{44}$. Siguiendo a Bergero, podemos decir que una delgada línea dividía a las dos altas sociedades del siglo XIX, la de la Gran Aldea y la del Ochenta, marcándose con nitidez en los objetos que amueblaban sus respectivos "espacios sagrados". Mientras los austeros patricios ostentaban sables y daguerrotipos de los Padres Fundadores, los espacios de la moderna alta sociedad estaban signados por las chinoiseries, las grandes escaleras y las estatuas de París ${ }^{45}$. Pero a pesar del dispendio de sus socios, el Club, hacia 1880, no había conseguido alcanzar el nivel de sofisticación de sus modelos europeos. La misma noche del baile, luego de declarársele a Blanca, Julio la conduce al come-

42. BRANDARIZ, Gustavo A., El Palacio Muñoa..., pp. 53-54.

43. Ibid., p. 55.

44. GÁLVEZ, Lucía, Club del Progreso..., p. 47.

45. BERGERO, Adriana, Intersecting Tangos..., p. 16. 
dor, en donde imperan el mal gusto en el ornato y una dudosa calidad gastronómica:

"Entramos en el comedor que todos conocemos: un gran salón al cual le falta mucho para estar bien puesto. Aquella noche, Canale, como de costumbre, había formado la gran mesa en herradura con mesas centrales, y sobre ella, había levantado los mismos catafalcos de cartón y pastas de azúcar de todos los años. Se cena execrablemente en el Club del Progreso, y el adorno de la mesa tiene mucho de los adornos de iglesia: los jamones en estantes de jalea, los pavos y las galantinas" ${ }^{\prime \prime}$.

La Gran Aldea es una "novela en clave" dirigida a un público que conocía sus personajes, situaciones y escenarios. La complicidad y la familiaridad que estableció López con sus lectores, todos miembros de la alta sociedad que frecuentaba el Club, hoy son imposibles de ser reconstruidos. Gran parte de los significados transmitidos allí se han perdido para siempre. Pero en 1884 las cenas "execrables" de este restaurante, así como la labor de Canale, quien podemos suponer se desempeñaba como chef o como encargado del local, eran cuestiones harto conocidas por "todos". Este "todos" bien podría traducirse como "toda" la alta sociedad porteña en la década de 1880. López, en este pasaje, ya no rememora, sino que describe una realidad presente, contemporánea a su escritura.

En lo que atañe a la gastronomía podemos decir que el ideal de una cocina Cordon Bleu no sería alcanzado ni siquiera a fines del XIX, y que las concesiones a la dieta local, con sus aportes criollos, españoles e italianos eran habituales. Si hasta la decoración parecía, según López, "de iglesia", con todo lo peyorativo que esto implicaba en un liberal anticlerical como él. Las comparaciones con el modelo europeo, en especial con el francés, son constantes en $\mathrm{La}$ Gran Aldea. Así, cuando habla de la escalera del Club, López la parangona desfavorablemente con la del Palacio del Elíseo, en París, sede de la presidencia de la República Francesa. El novelista adhiere con admiración a la cultura del II Imperio y a su decorativismo heredado de las fastuosas cortes de la Grandeur Française $^{47}$ :

"¿Quién no conoce el Club en una noche de baile? La entrada no es por cierto la entrada del palacio del Elíseo y la escalera no es una maravilla de arquitectura. Sin embargo, para el viejo porteño que no ha salido nunca de Buenos Aires, o para el joven provinciano que recién llega de su provincia, el Club es, o era en otro tiempo, algo como una mansión soñada cuya crónica está llena de prestigiosos romances y en el cual no es dado penetrar a todos los mortales" ${ }^{\text {"48 }}$.

46. LÓPEZ, Lucio V., La Gran Aldea..., p. 103.

47. BRANDARIZ, Gustavo A., El Palacio Muñoa..., p. 55.

48. LÓPEZ, Lucio V., La Gran Aldea..., p. 88. 
Nuevamente, el novelista propone una relación cómplice con su lector, el cual conoce el Club al dedillo como él, tanto en lo que hace a sus limitaciones estéticas como en su exclusividad social. El Club del Progreso podía no estar a la altura de sus paradigmas del Viejo Mundo pero no dejaba por ello de ser el recinto restringido de una elite, al que no entraba cualquiera. El dinero no era suficiente para poder ingresar a este grupo sino que era necesario un elemento impalpable, simbólico: el "ser conocido", una noción que remite a una intimidad familiar en el trato, a unas redes y a unos orígenes sociales que sirven de barrera contra los advenedizos ${ }^{49}$. El propio López lo dice explícitamente:

"La entrada era cosa ardua, no entraba cualquiera; era necesario ser crema batida de la mejor burguesía social y política para hollar las mullidas alfombras del gran salón o sentarse a jugar un partido de whist en el clásico salón de los retratos" 50 .

Aunque objetivamente distase mucho de lucir como una "mansión soñada" el Club lo era en un sentido subjetivo, por lo que significaba desde un punto de vista social, y porque había un discurso y un relato que lo sacralizaban. La pertenencia al Club confería un estatus y una identidad que les estaban vedados a la mayoría de los porteños. López resalta esto, más allá de que, en el momento de escribir su propia y anti-oficial crónica, la declinación de esta entidad ya se avizoraba. Cuando fue fundado en 1882 el Jockey Club aún no podía competir con el Club del Progreso, pero sí podría hacerlo con holgada ventaja en 1897, al inaugurar su sede de la calle Florida 571. Ésta fue proyectada por el arquitecto vienés M.A.Turner y terminada por Alejandro Christophersen. Uno de sus más preclaros socios, el escritor y embajador argentino en París, Miguel Cané, envió cortinados, alfombras, panoplias, arañas y faroles para el frente del edificio, mientras el presidente del Jockey, Carlos Pellegrini, se ocupó de manera directa de la construcción y del decorado, aportando los elementos materiales asequibles en Buenos Aires.

La enorme escalera de mármol y la estatua de la diosa Diana emplazada en el primero de sus descansos, obra del escultor francés Alexandre Falguière (1831-1900), fueron idea de Pellegrini, quien concibió y discutió epistolarmente los detalles del diseño con su amigo Cané. Adquirida a Julia del Valle, una dama de la alta sociedad porteña, la estatua, colocada en aquel imponente contexto, se convirtió en un símbolo de aristocracia, espiritualidad y arte, que parecía elevar a los extasiados visitantes a una esfera superior, de orden inmaterial. Así lo señala Pellegrini, en carta a Cané, el 2 de septiembre de 1897:

49. LOSADA, Leandro, La alta sociedad..., p. 270.

50. LÓPEZ, Lucio V., La Gran Aldea..., p. 89. 
"Y, en efecto, el hall es hermosísimo, pero todo desaparece ante la escalera soberbia, que se levanta y desarrolla en una curva armoniosa, brillando el ónix, cuyos matices realzaba una hermosísima alfombra. Alta en el primer descanso un foco de luz divina, la Diana ideal parece que va a elevarse lanzando la flecha que sus ojos miran e irradiando en torno una aureola de arte que envuelve la escalera entera y hace de todo el conjunto artístico, una de esas trouvailles, que es necesario ver. La masa no se explica en qué consiste la impresión que recibe, tan íntima y es ese mármol, que va a producir una revolución en nuestros gustos" $"$.

Estamos aquí muy lejos de la modesta escalera del Club del Progreso que tan impiadosamente describe López. En el Jockey, los habitantes de la "otra" Buenos Aires se verían desplazados por una experiencia transculturadora, que establecía las barreras de la exclusión de un modo mucho más nítido, sin necesidad de palabras. El "hechizo" que provocaban las escaleras era suficiente para inducir actos de reverencia, como sacarse los sombreros. Pero volviendo al Club del Progreso es de destacar el afán educativo presente en el momento de su fundación. El mismo se traducía en los principios democráticos que regían su reglamento, en la organización de bailes y en la búsqueda de una estética europea de los espacios interiores. A esto se agrega la biblioteca y la compra sistemática de diarios y revistas. Estas colecciones, debidamente encuadernadas, conformarían la hemeroteca más grande del país ${ }^{52}$. Para López, sin embargo, la empresa educativa había sido un fracaso. Los libros no eran tantos como hubieran debido ser y lo que en realidad predominaba eran los interminables volúmenes conteniendo insulsas publicaciones periódicas que nadie leía:

"Hasta hace muy poco, la biblioteca no era muy copiosa que digamos. Mucha Memoria, mucho Registro Oficial, pero a condición de no encontrarse nunca cuando se pedían; y en la mesa de lectura, todos los diarios porteños, vacíos y estériles como sábanas de monja [...] En la mesa de lectura el Illustrated London News y la Revue (casi sería inútil agregar de Deux Mondes, si no habláramos en el club) [...] y algunos diarios franceses que casi siempre sirven de adorno [...] cualquiera creería que allí se lee... ¡nada de eso! Allí se conversa: en el grupo de muchachos alegres y espirituales, que entra a las 12 de la noche repitiendo la última nota de Tamagno, no falta un ejemplar de denso burgués pantagruélico, gastrónomo, noctámbulo, engordado y enriquecido por el vientre libre de sus vacas, que se hace servir allí mismo un chorizo por noche, mientras que, con el profundo desdén del bruto feliz, descuidado el traje, pelado a la mal-content, mira todo lo que lo rodea con satisfecha apatía, llevando la mano

51. NEWTON, Jorge; NEWTON, Lily, Historia del Jockey Club de Buenos Aires, Buenos Aires, Ediciones L.N., 1966, p. 111.

52. GÁlVEZ, Lucía, Club del Progreso..., p. 47. 
al renegrido cabello y dragándose la caspa de aquella mollera inerte con la uña afilada del índice" ${ }^{\prime 53}$.

Los escritores del '80 eran grandes conversadores, lo cual influyó en su prosa fragmentaria. Dandies y hombres orquesta que abarcaban varias actividades, sin profundizar en ninguna, su producción careció de una sistematicidad de largo aliento. Es por ello que, en el género novelístico, las obras escasearon y hubo que esperar hasta el siglo XX para que los novelistas alcanzaran una creatividad más sostenida. La Gran Aldea es una de las pocas novelas decimonónicas escritas en el país pero también peca de cierta falta de organicidad, denunciada por la crítica literaria. Este carácter fragmentario de la literatura constituye la nota distintiva del panorama finisecular. El Club, aunque no fuera frecuentado sólo por intelectuales sino por miembros de una alta sociedad que se situaba en el primer escalón del refinamiento y de la ilustración, se hallaba en sintonía con esta tendencia. Aquel inmenso cúmulo de material escrito, que nadie leía, no era ni siquiera el compendio de saberes sistematizados y de obras clásicas, sino un caos de documentos sin valor.

El Club del Progreso había sido concebido como la escuela elemental de una civilización a alcanzar un día utópico, cuyos primeros rudimentos pretendían impartirse en una alta sociedad recientemente enriquecida, de origen plebeyo y sin el linaje de otras elites urbanas de Hispanoamérica. Para compensar esta carencia, la hemeroteca pretendía tender un puente de comunicación con Europa. Al mismo tiempo, una incipiente tradición histórica porteña y nacional pretendía implantarse, aunque fuese visualmente. Es el caso de la galería de retratos de grandes hombres, entre ellos los de los generales José de San Martín, Manuel Belgrano, Carlos María de Alvear y Juan Lavalle, así como los del presidente Bernardino Rivadavia, y el de Diego de Alvear, entre otros. Pero aunque el Club del Progreso produjera los hombres públicos que dirigían a Buenos Aires y al país, seguía navegando en el océano de improvisación y de falta de preparación que López repudiaba, sobre todo al contraponerlo con los prohombres que habían forjado la Independencia, aquellos patricios que la tradición criolla, amenazada por la invasión cosmopolita, la modernización y la degradación moral, reivindicaba como pilares:

"El Club del Progreso ha sido la pepinera de muchos hombres públicos que han estudiado en sus salones el derecho constitucional; literatura fácil que se aprende sin libros, trasnochado sobre una mesa de ajedrez; iy yo, no sé por qué, se me ocurre que algunos de los retratos de los hombres de Mayo que presencian aquel grupo de pensadores, hacen una mueca cada vez que un pollo acompa-

53. LÓPEZ, Lucio V., La Gran Aldea..., p. 90. 
ña un discurso sobre la libertad de sufragio con un golpe que asienta sobre el damero una reina jaqueada por la chusma de los peones sobrevivientes!"54.

A pesar de todo, los salones del Club, una institución eminentemente masculina, se convirtieron en el más elegante lugar de encuentro entre ambos sexos. Desde su fundación, los bailes mensuales, las tertulias y los bailes de Carnaval tuvieron lugar, primero en Perú 135, luego en el Palacio Muñoa, convirtiéndose en los eventos sociales más multitudinarios y prestigiosos de la alta sociedad. Desde 1862, los bailes y tertulias ganaron en lujo y refinamiento, tal como lo evidencian la reparación constante de cortinas, alfombras y tapizados, el lustrado de muebles, la profusión de flores y perfumes en el denominado Salón de las Señoras, la instalación del moderno sistema de iluminación a gas, así como la importación de los más finos cigarros y vinos ${ }^{55}$. ¿Pero qué aspecto tenían los bailes del Club en los ojos severos de Julio Rolaz? Para quien era más testigo que protagonista de los hechos, el espectáculo de esta sociedad materialista y aún pueblerina resultaba patético:

“¡Pero qué variado espectáculo! ¡Cuánta mujer ideal y atrayente bajo la trama cariñosa de esas telas modernas, cómplices de la carne y del contorno que este siglo materialista teje con alas de pájaro o pétalos de flores exóticas! ¡Cuánto ser grotesco de fealdad repugnante [...] marcando la nota chillona del ridículo! [...] ¡Cuánta mamá achatada por la gente que pasa, sirviendo de mojón en los sofás de lampás crema! ¡Cuánto marido tolerante que entrega su mujer a la garra de los halcones y que se sitúa en el buffet con el sentido práctico de un convencido! ¡Cuánto viejo fatuo, teñido de pies a cabeza [...] que apesta a menta desde lejos y que instala sus pretensiones intolerables ante cualquier mujer bonita" 56 .

Esta galería de personajes decadentes recorre La Gran Aldea, haciéndose más nutrida y rimbombante al momento de retratar la feria de vanidades que era el baile del Club. Como señala Foster, cuando los esquemas narrativos de esta novela trabajan con el propósito de mostrar las "costumbres bonaerenses" el panorama que nos deja el narrador es aquel en el que las estructuras ideológicas dominantes carecen de todo punto en común con individuos como Julio Rolaz $^{57}$. Individuos que, podríamos agregar, son marginales por definición. Así, no hay manera de redimir esta sociedad corrupta que, lejos de progresar moralmente bajo el ala protectora de los principios del Club, de la creciente prosperidad y del fin de la guerra, no hace más que seguir degradándose. Un espíritu

54. Ibid., p. 89.

55. GÁLVEZ, Lucía, Club del Progreso..., p. 63.

56. LÓPEZ, Lucio V., La Gran Aldea..., pp. 91-92.

57. FOSTER, David W., La gran aldea..., p. 85. 
por completo diferente y superador, es el que anima el intercambio epistolar entre Pellegrini y Cané, veinticinco años después. Hacia 1897, la Gran Aldea ha quedado definitivamente atrás. El baile inaugural del Jockey supone la consumación plena de aquellos utópicos principios que intentaran concretar, en vano, los fundadores del Club del Progreso. El 30 de septiembre de 1897 mil personas asisten al evento, sin que ocurra ningún incidente. Para Pellegrini el interior del nuevo edificio provocaría un cambio civilizatorio, y no sólo estético. Veamos lo que dice en una carta a Cané, no fechada y posterior al baile:

"La causa de este orden maravilloso, que a todos, nacionales y extranjeros, ha sorprendido, te lo explica esto: 'la casa impone'. Pocos eran los iniciados y pocos se imaginaban lo que iban a ver. El efecto lo estuvimos observando; era instantáneo. Con el cuello del sobretodo levantado, el sombrero puesto y los pantalones doblados, los hombres solos empujaban una puerta cancel y entraban de la calle sans façon, daban unos pasos y se quedaban clavados, se sacaban el sombrero lentamente y miraban en torno con ojos de asombro. Desde ese momento, el indio más guarango quedaba vencido y dominado y todo su anhelo era que no lo fueran a descubrir que no estaba en su centro" 58 .

Eran precisamente los principios fundacionales del Club del Progreso, magnificados en el Jockey, los que se materializan en esta ceremonia de 1897. Siguiendo a Bergero, podemos decir que Pellegrini, con su escalera, hace lo mismo, en esencia, que el general Roca con la frontera indígena ${ }^{59}$. En Buenos Aires no había tolderías araucanas pero sí una masa informe de inmigrantes y de proletarios que compartían con la alta sociedad el espacio urbano. Frente a su amenaza, la alta sociedad, al fin cristalizada en el Jockey, podía trazar una frontera infranqueable basada en principios estéticos y espirituales, que enmascaraban las diferencias de clase. Antes de 1880, este grupo no se hallaba "civilizado", y el Club del Progreso acogía a un grupo malintencionado y tosco:

"En esta última sala, larga y fría como un zaguán, que ha sido empapelada cien veces por lo menos de verde o celeste claro y que ha consumido cincuenta distintas partidas de tripe [...] ha nacido una generación de la cual van quedando muy escasos representantes. Allí ha mordido la maledicencia urbana a los jugadores trasnochadores, a los maridos calaveras, a la juventud disoluta y disipada, y cada mordisco de mamá indignada ha hecho los estragos de la viruela en el retrato moral de las víctimas. La maledicencia de la gran aldea es como la calumnia del Barbero de Sevilla: del venticello pasa al huracán"60.

58. NEWTON, Jorge y Lily, Historia del Jockey Club..., pp. 110-111.

59. BERGERO, Adriana, Intersecting Tangos..., p. 19.

60. LÓPEZ, Lucio V., La Gran Aldea..., p. 89. 
En 1884, López está haciendo ya un balance histórico del Club, que existe desde hace treinta y dos años y cuya generación fundacional está en vías de extinción, no sólo porque sus miembros han fallecido en su mayoría sino porque sus principios morales han caducado. A partir de 1880, con la elección de Julio Argentino Roca como Presidente de la Nación, se inicia el "Régimen" asentado sobre la "Alianza de los Notables", casi todos socios del Club. En los años finiseculares que siguen la alta sociedad se torna más austera, más rígida y más machista. La separación espacial y social entre ambos sexos se acentúa, a tal punto que las mujeres no pueden salir más solas. Con la mudanza del Club a la Avenida de Mayo en 1900, cambia su carácter criollo para ser como cualquier club inglés, "donde los privilegiados eran los hombres"61. De la lectura de La Gran Aldea o de En la sangre, cuyos autores eran socios del Club, se deduce que la sociedad anterior al 900 era más abierta y menos pacata. Había más naturalidad en el trato entre los jóvenes, una naturalidad que se iría perdiendo al adquirir la sociedad porteña características más afines a la moral victoriana. Desde 1900, el Club devendría un espacio de sportsmen que se reunían para charlar de política, de caballos y de "señoritas livianas"62.

Hacia fines del XIX el Palacio Muñoa había perdido buena parte de su esplendor original, deteriorado por el paso del tiempo y opacado por la flamante sede del Jockey Club. Es por ello que Roque Sáenz Peña, presidente del Club del Progreso durante diez períodos, resolvió atender las demandas de los socios más jóvenes. Poco antes de ser abandonado, el Palacio Muñoa fue renovado con la instalación de una sala de armas y otra de tiro al blanco, así como con nuevos baños provistos de duchas ${ }^{63}$. Para este entonces las posibilidades de ingresar a la alta sociedad eran mucho menores que antes, porque las tierras estaban repartidas y sobrevaluadas. La sociedad en su conjunto había dejado de ser flexible, "de frontera", y signada por la movilidad social ascendente. Parejamente, el mercado matrimonial se cerró, al igual que el acceso a las cimas del poder y de la riqueza ${ }^{64}$. El 24 de noviembre de 1900, en un artículo de El Diario titulado "Un viejo centro social que renace", se describe el nuevo edificio de cinco plantas, con ventanas, balcones y terraza que dominan la Avenida de Mayo. Tras hablar de los viejos buenos tiempos del Palacio Muñoa, de los lucidos y elegantes bailes de antaño, el artículo señala:

"La ubicación es, en nuestro concepto, de mano maestra [...] Desde sus balcones, el golpe de vista es magnífico. La Avenida de Mayo está, en esas primeras

61. GÁLVEZ, Lucía, Club del Progreso..., p. 74.

62. LUNA, Félix, El medio siglo del Club..., pp. 94-95.

63. GÁlVEZ, Lucía, Club del Progreso..., p. 74.

64. LOSADA, Leandro, La alta sociedad.., pp. 272-273. 
cuadras, totalmente edificada: la impresión que produce, vista desde arriba es la de un boulevard parisién [...] Agréguense a ello, el movimiento de carruajes, incesante frente al local y seguramente se participará de nuestra opinión"65.

El Club se había integrado a un contexto urbanístico y arquitectónico completamente diferente al descrito por López. Si el Palacio Muñoa había dominado la Gran Aldea de techumbres bajas la flamante sede formaba parte ahora de un boulevard inmenso, de inspiración parisina y "haussmaniana". Pero el cambio no era sólo funcional y estético, sino también ideológico y social. Los interiores se habían ampliado, incorporando ascensor, baños, un subsuelo con sala de armas, y una planta baja de decoración elegante y sobria, con salas para lectura y para reuniones. Todos estos espacios convergían en un hall blanc. Entre ellos se destacaba un comedor cuyos ventanales daban a la Avenida. A este conjunto se agregaba una amplia azotea, otro punto de conexión directa con el boulevard ${ }^{66}$.

En el corazón mismo de la antigua urbe colonial había nacido una nueva y ambiciosa dimensión, que iba más allá de los petits hôtels y de los clubes sociales. Apelando a una escala grandiosa, incorporando edificios de varios pisos, cuidados espacios verdes y vastos espacios cívico-ceremoniales que implicaban el despliegue de sociabilidades de masas impensables en el siglo ya fenecido, una dimensión exterior moderna se desarrollaba en vísperas del Centenario, diferenciándose sustancialmente de aquella que, con humilde pequeñez, había existido en la era criolla. La ciudad burguesa, la fastuosa y europeizante Capital Federal, había desplazado definitivamente a la Gran Aldea.

\section{Conclusiones}

Hemos procurado demostrar que las identidades de clase y las sociabilidades desplegadas en los espacios interiores se vincularon desde siempre en Buenos Aires. Durante la era criolla los escenarios casi exclusivos de las mismas fueron las casonas de la elite local, en donde los diferentes sectores sociales cohabitaban. Aunque las jerarquías no dejasen de estar establecidas, la configuración patriarcal de los núcleos residenciales, en donde coexistían, en un mismo y amplio espacio, miembros de una misma familia extendida, criados, esclavos y eventuales huéspedes, favorecía los intercambios interpersonales entre gentes de condición socioeconómica diversa. La sencillez de la vida cotidiana en general, traducida en la escasez de comodidades y en la austeridad de la decoración, del mobiliario, del vestido, de las bebidas y de los alimentos, así como en la

65. GÁlVEZ, Lucía, Club del Progreso..., p. 102.

66. Ibid., pp. 102-103. 
informalidad del trato, equiparaba "hacia abajo", limando las diferencias de clase. Por el contrario, durante la era aluvial la prosperidad y la tensión entre la elite criolla y los inmigrantes proletarios, impulsaron una diferenciación socioeconómica más aguda. Mientras los viajes a Europa se hacían más frecuentes y las familias más distinguidas comenzaban a abandonar el casco histórico para mudarse a sus petits hôtels del Barrio Norte, las formas de sociabilidad cambiaron, adoptando un claro sentido clasista.

En momentos en que la alta sociedad sustituía a sus humildes tertulias por salones de vocación parisina, en donde el lujo y la etiqueta rigidizaban el trato interpersonal, eran fundados sus clubes exclusivos, cuyas instalaciones eran tan lujosas y confortables como las de los petits hôtels, y harían las veces de escuelas elementales de refinamiento y civilidad. Hemos visto también cómo la transformación de la alta sociedad porteña en una verdadera aristocracia poseedora de la misma distinción y tren de vida que las del Viejo Continente, fue un proceso a largo plazo y de compleja resolución. El testimonio histórico-literario de Lucio V. López nos ha dado la pauta de esta situación así como también del desfasaje existente entre los abstractos y ambiciosos principios fundacionales del Club del Progreso, por un lado, y la tosca realidad de sus miembros, por el otro. En la década de 1880 la alta sociedad de Buenos Aires era, como el país entero, un proyecto a futuro. Sobre fines del XIX, en contrapartida, la Argentina moderna ya se había configurado, tanto en la faz material como ideológica, y con ella su alta sociedad. El Centenario de 1910, punto cúspide de la Belle Époque argentina, sería sin embargo el canto de cisne de esta joven y opulenta aristocracia. A partir de la reforma electoral de 1912 y del ascenso al poder de la Unión Cívica Radical, con la elección de Hipólito Yrigoyen como presidente de la Nación en 1916, la alta sociedad de Buenos Aires sería desplazada de la exclusividad del poder político. Sería entonces el turno de las clases medias y de los sectores populares, ambos de origen mayoritariamente inmigratorio. La declinación de los clubes exclusivos sería ostensible, y correría paralela a la declinación de la alta sociedad en general. Pero esa es otra historia, que excede los límites de nuestra investigación. 